\title{
The new credo: induction chemotherapy in locally advanced gastric cancer: consequences for surgical strategies
}

\author{
Katja Ott ${ }^{1}$, Florian Lordick ${ }^{2}$, Ken Herrmann $^{3}$, Bernd-Joachim Krause ${ }^{3}$, Christoph Schuhmacher ${ }^{4}$, \\ and JÖRG RÜDIGER SIEWERT ${ }^{5}$ \\ ${ }^{1}$ Department of Surgery, University of Heidelberg, Im Neuenheimer Feld 110, 69120 Heidelberg, Germany \\ ${ }^{2}$ National Center for Tumor Diseases, Department of Medical Oncology, Heidelberg, Germany \\ ${ }^{3}$ Department of Nuclear Medicine, Technische Universität München, Munich, Germany \\ ${ }^{4}$ Department of Surgery, Technische Universität München, Munich, Germany \\ ${ }^{5}$ Directorate, University Hospital Heidelberg, Heidelberg, Germany
}

\begin{abstract}
Perioperative chemotherapy in stage II and stage III gastric cancer is now accepted as a standard of care in the Western world. Two randomized phase III studies have shown improved survival for patients with induction chemotherapy followed by surgery compared with surgery alone. It is generally accepted that patients who respond to induction therapy have a significantly improved survival compared with that in nonresponding patients. Unfortunately no prospectively tested markers predicting response and/or prognosis are available for clinical practice. In adenocarcinomas of the esophagogastric junction (AEG), fluorodeoxyglucosepositron emission tomography (FDG-PET) prospectively was established as a surrogate predicting response and prognosis. The MUNICON (Metabolic response evalUatioN for Individualisation of neoadjuvant Chemotherapy in oesOphageal and oesophagogastric adeNocarcinoma) I study confirmed prospectively the usefulness of early metabolic response evaluation and showed the feasibility of a PET-guided treatment algorithm. These findings are an important step forward in the tailoring of multimodal treatment in accordance with tumor biology. In gastric cancer, we have analyzed FDG-PET in a prospective study. In gastric cancer the issue is more complicated, because about $30 \%$ of gastric cancers cannot be visualized with sufficient contrast for quantification. Insufficient FDG uptake is mostly associated with diffuse-type gastric cancer with signet ring cells and mucinous content. In FDGavid patients, FDG-PET can be used for response evaluation, comparable to that in AEG. The prognosis of FDG-nonavid patients is similar to that in metabolic nonresponders. The addition of new tracers such as fluorothymidine may increase the sensitivity of PET in the future. Treatment concepts such as immediate resection after only 2 weeks of induction therapy with or without adjuvant treatment could be considered in metabolic nonresponders, or modified chemotherapy regi-
\end{abstract}

Offprint requests to: $\mathrm{K}$. Ott

Presented in part at the 7th International Gastric Cancer Congress, Sao Paulo, Brazil, 2007

Received: November 1, 2007 / Accepted: December 3, 2007 mens, possibly including biologically targeted drugs, could be considered in those with FDG-nonavid tumors.

Key words Response guided neoadjuvant treatment · Locally advanced gastric cancer

Induction chemotherapy in gastric cancer

Prognosis in gastric cancer is highly dependent on tumor stage at presentation. Western patients with locally advanced tumors who do not receive perioperative treatment have a poor prognosis $20 \%-30 \%$ 5-year survival [1]. Improving results with extended surgery, as in Japan, has not been reproduced in the Western world [2-4]. The potential benefits of giving chemotherapy before surgery are the downsizing and downstaging of the primary tumor and lymph node metastases, treating micrometastases early in the course of treatment, increasing the rate of curative resections, and alleviating tumor-related symptoms. A new and important aspect is the possibility to test in vivo the chemosensitivity of the primary tumor. This might influence the administration and the regimen applied postoperatively in the adjuvant setting. The feasibility of neoadjuvant treatment in locally advanced gastric cancer has been proven by numerous phase II studies with different treatment regimens [5-8]. Compared with the prognosis in historical controls, the prognosis of the neoadjuvantly treated patients seemed to be improved and toxicity was moderate in most studies $[6,9]$. In the preoperative phase, acceptance, compliance, and tolerance of the patients was high and the complete dose could be given in nearly all patients.

Recently, two randomized phase III studies with perioperative chemotherapy, showing a survival benefit for patients with perioperative chemotherapy followed 
by surgery compared with surgery alone have been presented [10, 11]. The Medical Research Council Adjuvant Gastric Infusional Chemotherapy (MAGIC) trial randomly assigned patients with resectable adenocarcinoma of the stomach or lower esophagus either to perioperative chemotherapy (250 patients) or to surgery alone (253 patients). Chemotherapy consisted of three preoperative and three postoperative cycles of intravenous epirubicin, cisplatin, and continuous infusional 5-fluorouracil (FU). Chemotherapy-related adverse effects were moderate. Postoperative complications and 30 -day mortality did not differ in patients with and without perioperative chemotherapy (46\% versus $45 \%$ and $5.6 \%$ versus $5.9 \%$, respectively). The resected tumors were significantly smaller and less advanced in $\mathrm{T}$ - and $\mathrm{N}$-stage in the group who underwent preoperative chemotherapy. With a median follow-up of 4 years, 149 patients in the group with perioperative chemotherapy have died, compared with 170 patients in the surgery-only group. Compared with patients receiving surgery alone, the patients with perioperative chemotherapy had significantly improved overall $(P=0.009)$ and progression-free survivals $(P<0.001)$. The 5 -year survival rate was $36 \%$ for patients with perioperative chemotherapy and $23 \%$ for patients with surgery alone [10]. In 2007, at the American Society of Clinical Oncology (ASCO) conference, the French presented their Fédération Nationale des Centres de Lutte Contre le Cancer (FNCLCC) Actions Concertées dans les Cancer Colorectaux et Digestifs-07 (ACCORD-07) Fédération Francophone de la Cancérologie Digestif (FFCD) 9703 trial, which confirmed these results. In this trial, a combination of infusional 5-FU and cisplatin, given for two to three cycles preoperatively, was delivered in patients with resectable gastric or esophageal adenocarcinoma [11]. Postoperative chemotherapy was recommended in patients with response to preoperative chemotherapy or in those with stable disease with positive lymph nodes. A total of 224 patients (111 patients with surgery alone and 113 patients with perioperative chemotherapy) were included. The rate of resections with tumor-free margins (R0) was significantly higher after preoperative chemotherapy $(84 \%$ versus $73 \% ; P$ $=0.04)$. After induction chemotherapy, the disease-free $(P=0.003)$ and overall survivals $(P=0.02)$ were superior to those in patients with surgery alone. The reported 5 -year survival rates of $38 \%$ with chemotherapy and $24 \%$ with surgery alone were similar to the rates in the MAGIC trial. In both studies, only a small percentage (MAGIC trial, 42\%; ACCORD-07, 50\%) of patients completed both pre- and postoperative chemotherapy, whereas in $86 \%$ and $87 \%$ of the patients preoperative chemotherapy was administered as specified in the study protocol. The results of both studies are summarized in Table 1. It is not possible to attribute the survival benefit to preoperative chemotherapy only, because both studies evaluated perioperative chemotherapy. The study design does not allow for a separate analysis of the impact of the postoperative chemotherapy on the improvement in overall survival.

Both studies have been criticized because of the long recruitment period ( 8 years each), the insufficient preoperative staging, the inaccurate histopathological workup, and the high dropout rate in the postoperative treatment arm. Neither a clinical nor a histopathological response evaluation was performed in either study.

Table 1. Randomized phase III studies in locally advanced gastric cancer comparing perioperative chemotherapy followed by surgery with surgery alone

\begin{tabular}{|c|c|c|c|c|c|c|}
\hline \multirow[b]{2}{*}{ Parameter } & \multicolumn{2}{|c|}{ MAGIC } & \multirow[b]{2}{*}{$P$} & \multicolumn{2}{|c|}{ ACCORD-07 } & \multirow[b]{2}{*}{$P$} \\
\hline & $+\mathrm{CTx}$ & $\mathrm{S}$ & & $+\mathrm{CTx}$ & $\mathrm{S}$ & \\
\hline Patients (no.) & 250 & 253 & & 113 & 111 & \\
\hline Surgery & 212 & 232 & NS & 109 & 110 & NS \\
\hline $\begin{array}{l}\text { Complete resection a } \\
\text { All patients } \\
\text { With radical surgery }\end{array}$ & $\begin{array}{l}\text { ding to } \\
69 \% \\
79 \%\end{array}$ & $\begin{array}{l}\text { surge } \\
66 \% \\
70 \%\end{array}$ & $\begin{array}{l}\text { NS } \\
0.018\end{array}$ & & & \\
\hline \multicolumn{4}{|c|}{ R category histopathologically } & $84 \%$ & $73 \%$ & 0.04 \\
\hline $\begin{array}{l}\text { pT012 } \\
\text { pN0 } \\
\text { Preoperative CTx } \\
\text { Completion CTx }\end{array}$ & $\begin{array}{l}52 \% \\
31 \% \\
86 \% \\
42 \%\end{array}$ & $\begin{array}{l}37 \% \\
27 \%\end{array}$ & $\begin{array}{l}0.002 \\
\mathrm{NS}\end{array}$ & $\begin{array}{l}42 \% \\
33 \% \\
87 \% \\
50 \%\end{array}$ & $\begin{array}{l}32 \% \\
20 \%\end{array}$ & $\begin{array}{l}0.16 \\
0.054\end{array}$ \\
\hline $\begin{array}{l}\text { Mortality } \\
\text { OS (log rank) } \\
\text { PFS (log rank) }\end{array}$ & $6 \%$ & $6 \%$ & $\begin{array}{c}\text { NS } \\
0.009 \\
<0.001\end{array}$ & $5 \%$ & $4 \%$ & $\begin{array}{l}\text { NS } \\
0.021 \\
0.0033\end{array}$ \\
\hline 5-Year survival & $36 \%$ & $23 \%$ & & $38 \%$ & $24 \%$ & \\
\hline
\end{tabular}

CTx, Chemotherapy; S, surgery alone; NS, not statistically significant; pT, pT category; pN, pN category; OS, overall survival; PFS, progression-free survival 
However, these points of criticism have probably been balanced in both arms of each trial due to randomization. Therefore, in the Western world these results are widely accepted, even if some questions remain open, and perioperative induction chemotherapy is widely used in Europe for locally advanced gastric cancer.

\section{Response evaluation}

Since 1999 it has been perceived that patients who respond to induction chemotherapy have a significantly improved survival compared to patients who do not respond to induction treatment [12]. However, no standardized concepts for response evaluation have been established so far. Clinical response evaluation by morphologic imaging techniques has specific limitations in gastric cancer. According to the strict WHO criteria, gastric cancer is not bidimensionally measureable [13]. Criteria from the Response Evaluation Criteria in Solid Tumor (RECIST) Group ratings, which use onedimensional measurements, are, in principle, applicable for gastric cancer [14]. However, the measurement of wall thickness is critically dependent on the distension of the stomach during the examination.

RECIST criteria have been used in only a few phase II trials with induction therapy so far [15-19]. Careful clinical response evaluation, with a combination of endoluminal ultrasound, endoscopy, and computed tomography (CT) scans used for restaging after one cycle or before surgery, is predictive of histopathological regression and prognosis at experienced centers [5, 12, 20-23].

Often histopathological regression is used for response evaluation. Yet including only patients who undergo resection would cause a significant bias; therefore, clinical response evaluation has to be included, and patients with progression during chemotherapy have to be classified as nonresponding. Although similar criteria for histopathological regression have been used in several studies, these criteria are not standardized and may be investigator-dependent. A modified regression score of Mandard et al. [24], who first described histopathological regression for esophageal cancer after chemoradiotherapy, was published by Becker et al. [25] for gastric cancer. Applying this scoring system, patients with less than $10 \%$ residual tumor cells after neoadjuvant treatment are classified as histopathological responders (score 1a, complete response and score $1 \mathrm{~b}$, less than $10 \%$ residual tumor cells). In other publications, only patients with complete tumor regression are classified as histopathological responders [26, 27]. In contrast, Shah et al. [28] defined patients with less than $50 \%$ residual tumor cells as histopathological responders.
All applied types of response evaluation, either clinical or histopathological, are strongly correlated with prognosis. Homogenization of the scoring systems used for clinical and histopathological response evaluation would be desirable in the future to make studies of induction therapy more easily comparable with each other.

\section{A model for metabolic response evaluation in adenocarcinomas of the esophagogastric junction (AEG)}

Measurements of early changes in tumor glucose uptake after only 2 weeks of induction therapy, with the use of 18-fluorodeoxyglucose-positron emission tomography (FDG-PET), have yielded reproducible results that can be used for the prediction of clinical and histopathological response after the end of neoadjuvant treatment in type I and II adenocarcinomas of the distal esophagus $[21,22]$. The cutoff value of a decrease of more than $35 \%$ of the initial standard uptake value (SUV) after 2 weeks of induction therapy predicted response and prognosis [21]. Our major interest was to correctly identify nonresponding patients early in the course of therapy, to avoid toxic, expensive, and ineffective treatment. The cutoff value was confirmed in an independent patient population [22]. Specifically, we have noted that, when using the cutoff value of $-35 \%$ decrease of initial SUV, PET correctly identifies nonresponding patients after 2 weeks of chemotherapy with a high accuracy [21, 22]. This finding was used to tailor treatment to the individual patient in the MUNICON trial (the Metabolic response evalUatioN for Individualisation of neoadjuvant Chemotherapy in oesOphageal and oesophagogastric adeNocarcinoma) [29, 30]. Metabolic responders after 2 weeks of induction chemotherapy continued to receive chemotherapy for a maximum of 12 weeks before undergoing surgery, whereas metabolic nonresponders discontinued chemotherapy and were immediately transferred to surgery after only 2 weeks of chemotherapy. In this trial, 110 patients were evaluable for metabolic response and $49 \%$ were classified as metabolic responders; 104 patients had resections. Histopathological regression with less than $10 \%$ residual tumor cells was achieved in $58 \%$ of the metabolic responders, but no histopathological regression $1 \mathrm{a}$ or $1 \mathrm{~b}$ was achieved in metabolic nonresponders. The median survival for metabolic responders has not yet been reached, whereas the median survival for metabolic nonresponders is 25.8 months $(P=0.015)$. The eventfree survival was 29.7 months for metabolic responders and 14.1 months in metabolic nonresponders $(P=0.002)$ $[29,30]$. Interestingly, metabolic nonresponders who had resections after only 2 weeks of induction therapy 
A

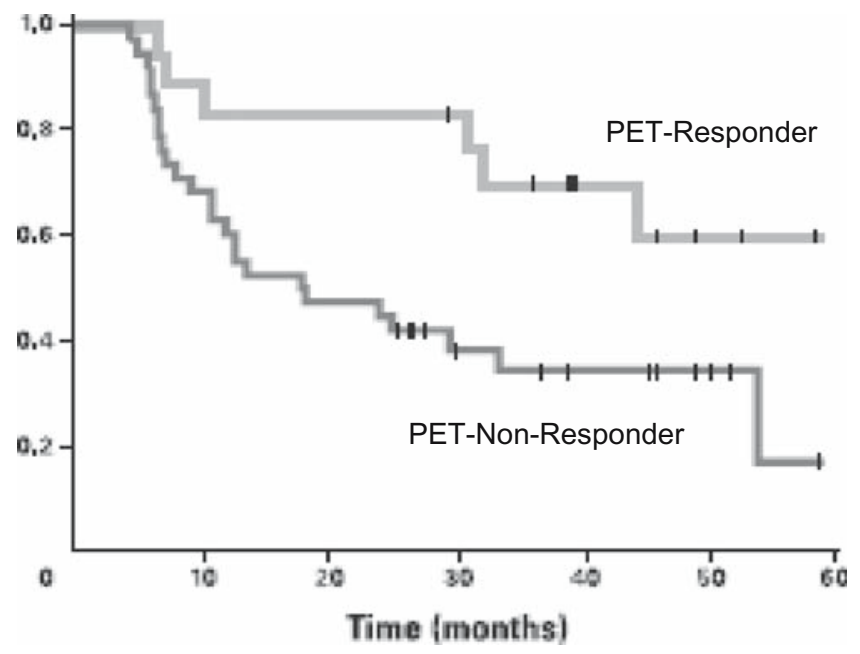

B

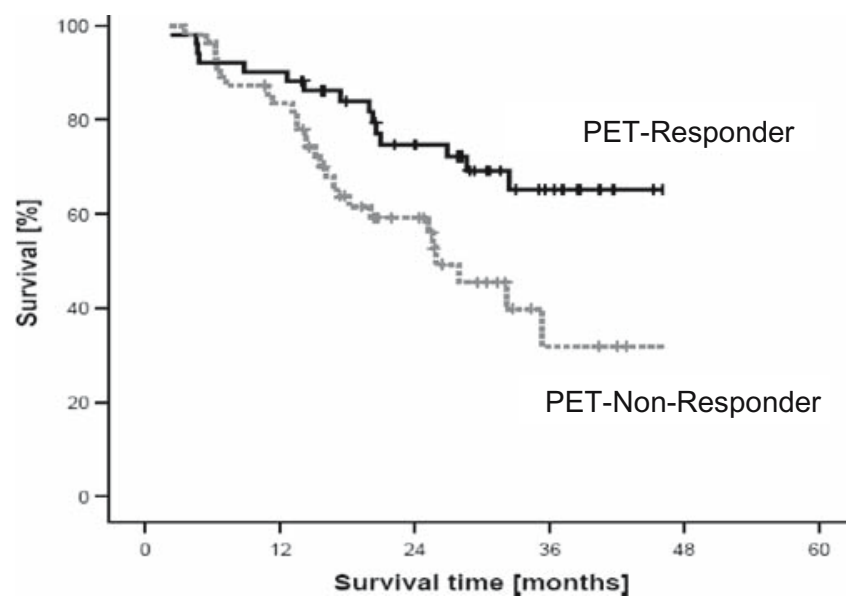

Fig. 1A,B. Historical comparison of overall survival of $\mathbf{A}$ patients with chemotherapy for 3 months and $\mathbf{B}$ patients with response-based neoadjuvant treatment. The median survival of metabolic (PET) nonresponders was 26 months in patients with immediate resection after 2 weeks of chemotherapy and 18 months in patients with 3-month chemotherapy in the historical control group. Stopping chemotherapy did not seem to worsen the prognosis of the metabolic nonresponders. PET, Positron emission tomography [22, 29]

had a slightly better survival compared to that of the historic control metabolic nonresponders who completed two cycles of neoadjuvant treatment (Fig. 1) $[22,29]$. The MUNICON study confirmed again, prospectively, the usefulness of metabolic response evaluation in AEG I and II and showed, for the first time, that a PET-guided treatment algorithm was feasible in the multidisciplinary treatment setting and that it led to favorable treatment results. Based on these results, the tailoring of multimodal treatment in accordance with individual tumor biology might be possible in future randomized trials.
Table 2. Incidence of FDG-nonavid tumors in gastric cancer

\begin{tabular}{lcccc}
\hline Author & Year & $n$ & Evaluable & Percentage \\
\hline Shah [28] & 2007 & 41 & 31 & 73 \\
Shah [41] & 2007 & 82 & 52 & 63 \\
Wang [39] & 2006 & 29 & 25 & 86 \\
Kim [35] & 2006 & 73 & 70 & 96 \\
Chen [36] & 2005 & 68 & 64 & 94 \\
Yun [40] & 2005 & 81 & 71 & 88 \\
Tian [37] & 2004 & 30 & 25 & 83 \\
Mochiki [38] & 2004 & 85 & 64 & 75 \\
Stahl [33] & 2003 & 40 & 24 & 60 \\
Ott [20] & 2003 & 44 & 35 & 80 \\
\hline
\end{tabular}

$n$, Number

\section{FDG-PET in gastric cancer}

In gastric cancer, current imaging modalities or molecular markers cannot reliably predict therapy response before or early in the course of treatment - the time when this information is most important in gastric cancer [31,32]. As noted above, PET imaging after 2 weeks of chemotherapy was significantly correlated with histopathological response and prognosis in patients with AEG I/II [21, 22, 29]. Interestingly, approximately one-third of gastric cancer patients, even those with locally advanced tumors, initially have insufficient FDG uptake for quantification (Table 2) [20, 28, 33-41]. FDG-nonavid tumors are associated with diffuse Lauren classification, small tumor size, good differentiation, mucinous content, and localization in the distal third (Table 3) [33-38, 41]. We have shown that a decrease in tumor FDG uptake by more than $35 \%$ of the baseline value allowed for accurate prediction of response in patients with gastric cancer 14 days after the initiation of cisplatin-based polychemotherapy, with an overall accuracy of $83 \%$ for 35 patients if image contrast was sufficient for quantitative analysis. Metabolic response in FDG-avid gastric cancer, including AEG II, showed an association with metabolic and histopathological or clinical response (Table 4). For patients with a metabolic response, median survival was not reached (2-year survival rate, $90 \%$ ); for patients without a metabolic response, median survival was 18.9 months (2-year survival, $25 \% ; P=0.002 ;$ Fig. 2) [20]. This study used a cutoff defining the metabolic response derived from patients suffering from locally advanced AEG after 2 weeks of induction therapy [21]. A different time point and cutoff value was determined by Shah et al. [28] for 41 patients with gastric cancer staged cT2-4NanycM0. They evaluated, retrospectively, a decrease of more than $45 \%$ of the initial SUV after 35 days as the best criterion for predicting response and prognosis. The cutoff was significantly correlated with histopathological response (less than $50 \%$ residual tumor; $P=0.007$ ) 
K. Ott et al.: Induction therapy in gastric cancer

Table 3. Correlation of FDG-nonavid tumor with clinical and histopathological parameters

\begin{tabular}{lcccccc}
\hline Author & Year & $\begin{array}{c}\text { Lauren } \\
\text { classification }\end{array}$ & $\begin{array}{c}\text { Mucinous } \\
\text { content }\end{array}$ & $\begin{array}{c}\text { Tumor } \\
\text { size }\end{array}$ & Grading & Localization \\
\hline Shah [41] & 2007 & Sign. & NA & NS & Sign. & Sign. \\
Mukai [34] & 2006 & NA & NA & Sign. & NA & NA \\
Kim [35] & 2006 & Sign. & NA & NA & NA & NA \\
Chen [36] & 2005 & Sign. & NA & Sign. & NA & NA \\
Tian [37] & 2005 & NA & NA & Sign. & Sign. & NA \\
Mochiki [38] & 2004 & NA & NA & Sign. & NA & NA \\
Stahl [33] & 2003 & Sign. & Sign. & NA & Sign. & NA \\
\hline
\end{tabular}

Sign., Statistically significant; NA, not analyzed; NS, not statistically significant
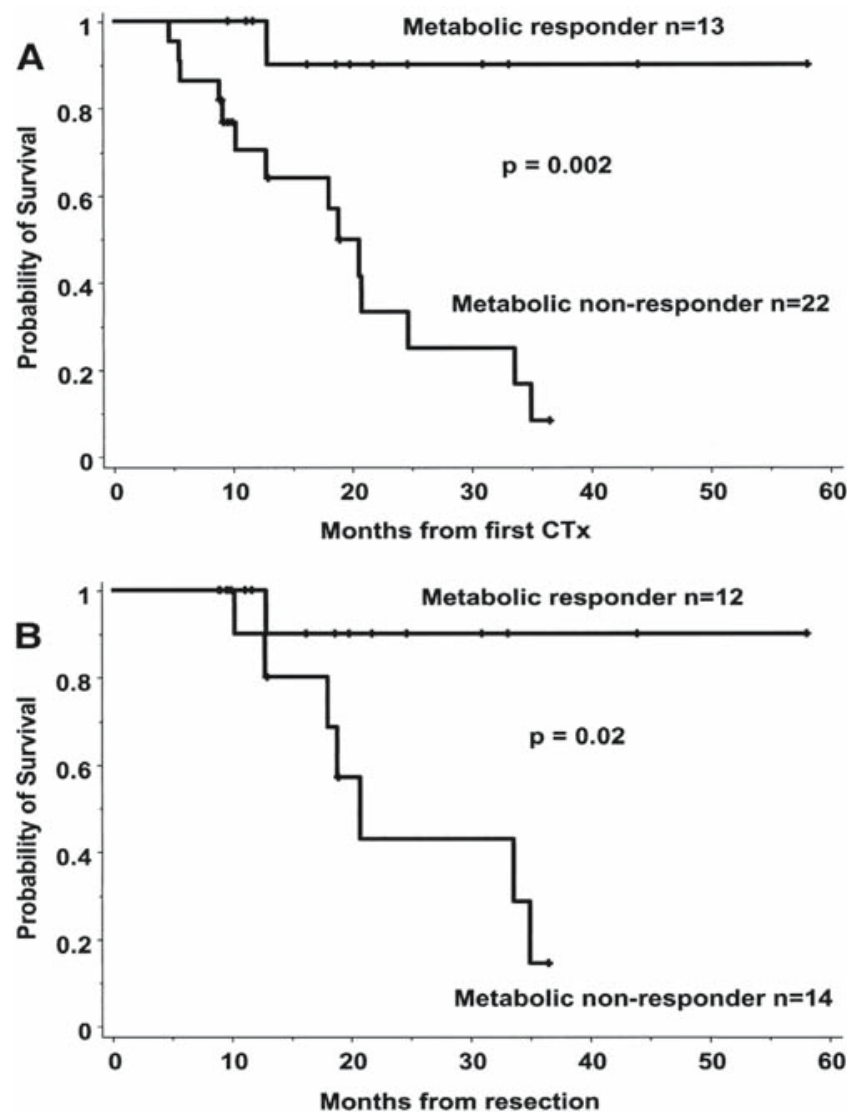

Fig. 2. A Overall survival of metabolic responders and metabolic nonresponders with locally advanced gastric cancer, calculated from the beginning of chemotherapy $(C T x)$. Metabolic responders had significantly improved survival compared to metabolic nonresponders $(P=0.002)$. B Overall survival in patients with locally advanced gastric cancer after complete resection, calculated from the day of the operation. Metabolic responders had significantly improved survival compared to metabolic nonresponders $(P=0.02)$

and disease-free survival $(P=0.01)$ [28]. Therefore, before these findings can be used routinely in the clinical setting these cutoffs have to be harmonized, and methodology has to be standardized and tested prospectively in a multicenter setting. Another open

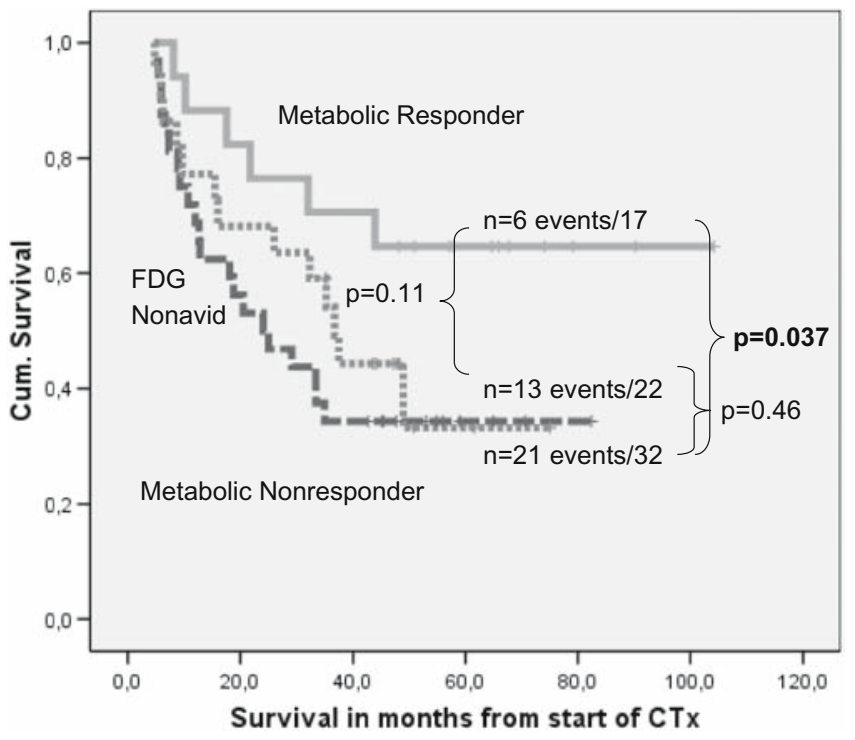

Fig. 3. Overall (cumulative; cum) survival of 18-fluorodeoxyglucose $(F D G)$-avid metabolic responders (continuous line), FDG-avid metabolic nonresponders (dashed line), and patients with FDG-nonavid tumors (dotted line). The prognosis of metabolic responders was significantly improved compared to that in metabolic nonresponders $(P=0.037)$. The prognosis of patients with FDG-nonavid tumors and the FDG-avid nonresponders were not significantly different $(P$ $=0.46)$. There was a trend for improved survival in metabolic responders compared to FDG-nonavid patients $(P=0.11)$

question is whether an early metabolic response evaluation is possible in patients with AEG and the stomach treated with preoperative chemoradiotherapy [8, 42]. No data addressing this problem are available so far. As noted above, up to $40 \%$ of gastric carcinomas are FDGnonavid and are therefore not suitable for response monitoring using the PET tracer 18F-FDG. Interestingly, the response rate and prognosis of these patients seems to be similar to those in metabolic nonresponders, probably defining a subgroup of biologically unfavorable tumors (Fig. 3; our own unpublished data). In a recent study with 45 patients, we compared fluorothy- 
Table 4. Association between metabolic and clinical or histopathological response in FDG-avid gastric cancer, including AEG I/II

\begin{tabular}{lclccc}
\hline Author & Year & Localization & $n$ & $\begin{array}{c}\text { Clinical response } \\
(P \text { value })\end{array}$ & $\begin{array}{c}\text { Histopathological } \\
\text { response }(P \text { value })\end{array}$ \\
\hline Weber & 2001 & AEG I/II & 40 & NA & 0.001 \\
Ott & 2003 & Gastric cancer & 44 & 0.0002 & 0.0002 \\
Ott & 2006 & AEG I/II & 65 & $<0.001$ & 0.001 \\
Shah & 2007 & Gastric cancer & 41 & NA & 0.007 \\
Lordick & 2007 & AEG I/II & 110 & NA & 0.001 \\
\hline
\end{tabular}

$n$, Number; NA, not analyzed
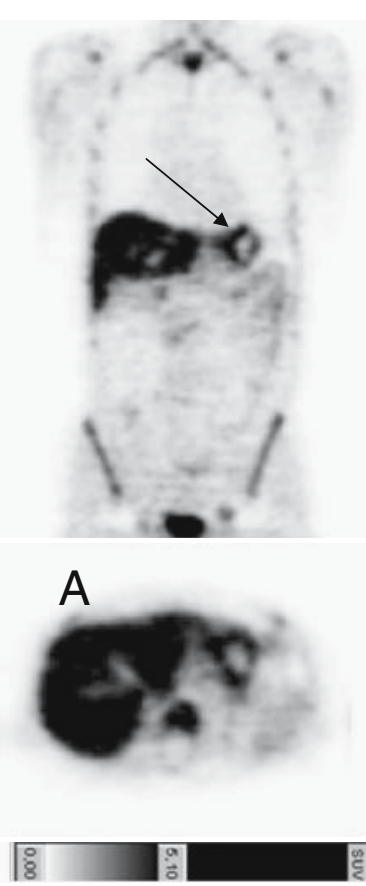
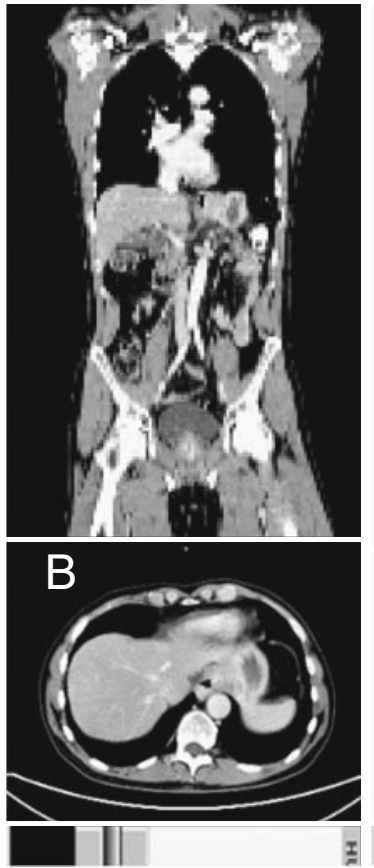
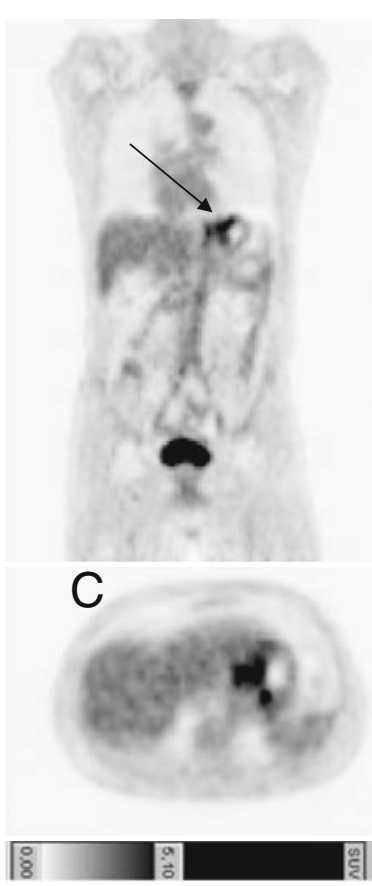

Fig. 4A-C. Visualization of locally advanced gastric cancer (arrows in $\mathbf{A}$ and C) with A FLT-PET, B computed tomography (CT), and C FDG-PET. FLT, fluorothymidine midine (FLT)-PET and FDG-PET for the detection of locally advanced gastric cancer. FLT-PET revealed a higher sensitivity than FDG-PET and might serve as a useful diagnostic adjunct reflecting the quantitative assessment of proliferation (Fig. 4). In the future, the addition of FLT-PET to FDG-PET could improve the early evaluation of response to neoadjuvant treatment of gastric cancer.

\section{Neoadjuvant treatment and surgical consequences in gastric cancer}

\section{Risk analysis}

Severe chemotherapy-related complications inhibiting resection after chemotherapy are relatively rare. In the MAGIC study, 4 of 237 patients in the perioperative chemotherapy group died within 60 days after commencing treatment: 2 because of tumor progression and
2 because of cardiac events. In the French study, 4 of 113 patients with perioperative chemotherapy did not have a resection: 1 patient died of toxicity-related causes and 3 did not have a resection because of tumor progression [10,11].

Postoperative mortality was the same in both treatment arms in both randomized phase III studies. In the MAGIC trial, in the surgery-alone arm, $5.6 \%$ of patients died and $5.9 \%$ died in the perioperative chemotherapyarm; in the French trial, the corresponding numbers were $4 \%$ and $5 \%$, respectively. The reported complication rate was higher in the MAGIC trial $(45.3 \%$ for surgery alone, $45.7 \%$ for perioperative chemotherapy) than in the French trial (19\% for surgery alone and 26\% for perioperative chemotherapy). This may have been be due to the inclusion of minor complications in the analysis. Median hospital stay in both groups in the MAGIC trial was 13 days $[10,11]$.

A matched-pair analysis, performed at the Technical University of Munich in 248 patients with neoadjuvant 
Table 5. Matched-pair analysis of 248 patients with neoadjuvant chemotherapy followed by surgery, and surgery alone, from the Technical University of Munich: type and incidence of complications

\begin{tabular}{lccc}
\hline Type of complication & Neoadjuvant CTx & Surgery alone & $P$ \\
\hline Insufficiency & $6.1 \%$ & $6.4 \%$ & 0.87 \\
At esophagojejunostomy & $4.0 \%$ & $4.0 \%$ & \\
At duodenal stump & $0.8 \%$ & $0.4 \%$ & \\
At enteroanastomosis & $0.8 \%$ & $2.0 \%$ & \\
At other site & $0.4 \%$ & $0.4 \%$ & 0.41 \\
Bleeding, intraluminal & $0.8 \%$ & $1.6 \%$ & 0.13 \\
Bleeding, extraluminal & $1.2 \%$ & $3.2 \%$ & 0.27 \\
Wound infection & $3.2 \%$ & $5.2 \%$ & 0.43 \\
Intraabdominal abscess & $6.9 \%$ & $5.2 \%$ & 0.02 \\
Peritonitis & $0 \%$ & $2.0 \%$ & 0.99 \\
Ileus & $1.2 \%$ & $1.2 \%$ & 0.47 \\
Cardiopulmonary & $6.5 \%$ & $8.4 \%$ & \\
CTx, Chemotherapy & & &
\end{tabular}

treatment compared to 248 with surgery alone, confirmed these results. The overall complication rate was $29.1 \%$ after neoadjuvant chemotherapy and $28.9 \%$ after surgery alone; the in-hospital mortality was $3.2 \%$ and $5.5 \%$; and the 30-day mortality was $2.0 \%$ and $2.8 \%$, respectively. The median hospital stay was 14 days in both groups. No difference regarding type or incidence of complications could be found between the two groups (Table 5).

\section{Histopathology and prognosis}

Significantly more complete resections were achieved in the French randomized trial $(87 \%$ versus $74 \% ; P=0.04)$ and in the Technical University of Munich matchedpair analysis (74\% versus $58 \% ; P=0.0001)$. No exact histopathological workup of the resected specimens was performed in the MAGIC trial. But a curative resection according to the surgeon was achieved in $69 \%$ of the patients with perioperative chemotherapy and in $66 \%$ of the patients with primary resection; the complete resection rate of patients treated with radical surgery was in favor of perioperative chemotherapy (79\% versus $70 \% ; P=0.018$; Table 1). In both the MAGIC and the French trials, there was a trend to lower $\mathrm{pN}$ categories following preoperative chemotherapy. In the MAGIC trial, $84 \%$ of the patients in the chemotherapy arm were pN0 or 1 compared to $71 \%$ in the surgery-alone arm $(P$ $=0.01$ ); in the French trial, $33 \%$ of the patients in the chemotherapy arm and $20 \%$ in the surgery-alone arm were classified as pN0 $(P=0.054)[10,11]$.

A downsizing of the primary tumor (pT0, 1 or 2$)$ occurred in $52 \%$ of the patients in the MAGIC trial $(P$ $=0.002)$ and in $42 \%$ of the patients in the French trial $(P=0.16)[10,11]$.

Both studies consistently showed significantly improved progression-free and overall survivals for the patients with perioperative chemotherapy and surgery.

In conclusion, the effectiveness and superiority of perioperative chemotherapy followed by surgery compared to surgery alone was proven by both the randomized phase III studies described here (the MAGIC and French trials). There was no difference in morbidity, mortality, hospital stay, and incidence or type of complications between the two treatment groups in either trial. Histopathological results were improved by perioperative chemotherapy.

\section{The new credo}

Recently published randomized phase III studies have shown that induction chemotherapy is effective in locally advanced gastric cancer $[10,11]$. Perioperative chemotherapy did not increase morbidity or mortality, but significantly improved the patients' survival [10,11]. It is generally accepted that responders have a significantly improved survival compared to that in nonresponding patients [12]. Unfortunately, no standardized scores for clinical or histopathological response evaluation have been established so far, which makes studies hard to compare [5, 22, 27, 28]. There is a need for the homogenization of clinical and histopathological response scores after induction chemotherapy. Thus far, no prospectively tested clinical, histopathological, or molecular markers predicting response and/or prognosis are available for gastric cancer before induction therapy is started. Only the metabolic response has predicted histological response and survival with sufficient accuracy [20, 28]. However, the relevant group of FDG-PET-nonavid patients makes the issue more complicated in gastric cancer than in AEG I and II [33, 34, 37, 38]. Response and survival for FDG-PET-nonavid patients was not 


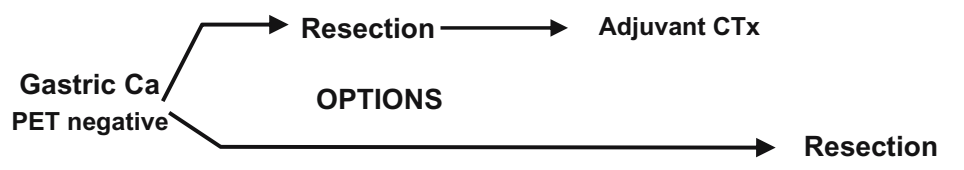

More intensive CTx/different regimens/targeted therapy/ high precision radiation

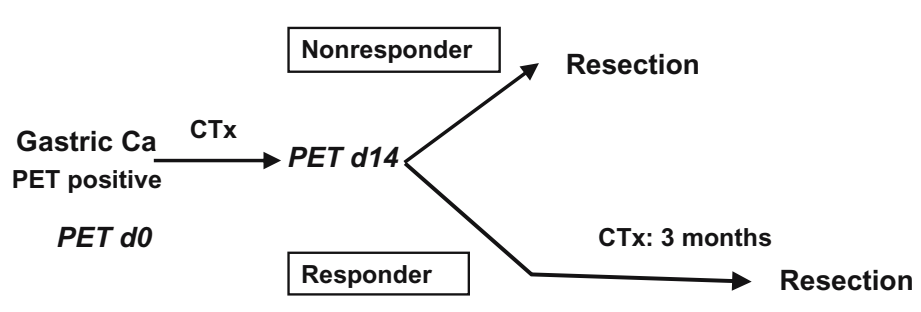

Fig. 5. Theoretical model of an individualized FDG-PET-based treatment strategy in locally advanced gastric cancer. $\mathrm{Ca}$, Cancer; $d$, day significantly better than that in metabolic nonresponders. Thus, alternative treatment concepts, such as immediate resection after 2 weeks of chemotherapy or adjustment of chemotherapy with or without adjuvant treatment for metabolic nonresponders, or modified or potentially more intensive perioperative chemotherapy regimens - possibly including biologically targeted drugs or intensity-modulated high-precision radiotherapy - in initially FDG-PET-nonavid tumors could be considered (Fig. 5). Generally, response-based strategies such as those in the MUNICON trial are feasible and recommendable in AEG I and II in clinical studies [29,30]. The results of the MUNICON trial have now to be confirmed in a prospective randomized multicenter trial. Because FDG-PET is less effective in gastric cancer than in AEG I and II for early response evaluation, other stratification criteria such as FLT-PET or histopathological or molecular markers may gain importance in gastric cancer. In summary, the design of individualized response-based treatment concepts to improve patient survival is the challenge of the future.

\section{References}

1. Roder JD, Bottcher K, Siewert JR, Busch R, Hermanek P, Meyer HJ. Prognostic factors in gastric carcinoma. Results of the German Gastric Carcinoma Study 1992. Cancer 1993;72:2089-97.

2. Bonenkamp JJ, Hermans J, Sasako M, Van de Velde CJ, Welvaart K, Songun I, et al. Extended lymph-node dissection for gastric cancer. N Engl J Med 1999;340:908-14.

3. Hartgrink HH, Van de Velde CJ, Putter H, Bonenkamp JJ, Klein $\mathrm{KE}$, Songun I, et al. Extended lymph node dissection for gastric cancer: who may benefit? Final results of the randomized Dutch Gastric Cancer Group trial. J Clin Oncol 2004;22:2069-77.

4. Hartgrink HH, Bonenkamp HJ, Van d, V. Influence of surgery on outcomes in gastric cancer. Surg Oncol Clin N Am 2000; 9:97-8.

5. Ott K, Sendler A, Becker K, Dittler HJ, Helmberger H, Busch $\mathrm{R}$, et al. Neoadjuvant chemotherapy with cisplatin, 5-FU, and leucovorin (PLF) in locally advanced gastric cancer: a prospective phase II study. Gastric Cancer 2003;6:159-67.

6. Schuhmacher CP, Fink U, Becker K, Busch R, Dittler HJ, Mueller $\mathrm{J}$, et al. Neoadjuvant therapy for patients with locally advanced gastric carcinoma with etoposide, doxorubicin, and cisplatinum. Closing results after 5 years of follow-up. Cancer 2001;91: 918-27.

7. Ajani JA, Mansfield PF, Lynch PM, Pisters PW, Feig B, Dumas $\mathrm{P}$, et al. Enhanced staging and all chemotherapy preoperatively in patients with potentially resectable gastric carcinoma. J Clin Oncol 1999;17:2403-11.

8. Ajani JA, Komaki R, Putnam JB, Walsh G, Nesbitt J, Pisters PW, et al. A three-step strategy of induction chemotherapy then chemoradiation followed by surgery in patients with potentially resectable carcinoma of the esophagus or gastroesophageal junction. Cancer 2001;92:279-86.

9. Ott K, Vogelsang H, Mueller J, Becker K, Muller M, Fink U, et al. Chromosomal instability rather than p53 mutation is associated with response to neoadjuvant cisplatin-based chemotherapy in gastric carcinoma. Clin Cancer Res 2003;9:2307-15.

10. Cunningham D, Allum WH, Stenning SP, Thompson JN, Van de Velde CJ, Nicolson M, et al. Perioperative chemotherapy versus surgery alone for resectable gastroesophageal cancer. N Engl J Med 2006;355:11-20.

11. Boige V, Pignon J, Saint-Aubert B, Lasser P, Conroy T, Bouche $\mathrm{O}$, et al. Final results of a randomized trial comparing preoperative 5-fluorouracil $(\mathrm{F}) /$ cisplatin $(\mathrm{P})$ to surgery alone in adenocarcinoma of stomach and lower esophagus (ASLE): FNLCC ACCORD07-FFCD 9703 trial (Meeting Abstract). J Clin Oncol 2007;25:4510.

12. Lowy AM, Mansfield PF, Leach SD, Pazdur R, Dumas P, Ajani JA. Response to neoadjuvant chemotherapy best predicts survival after curative resection of gastric cancer. Ann Surg 1999;229:303-8.

13. Miller AB, Hoogstraten B, Staquet M, Winkler A. Reporting results of cancer treatment. Cancer 1981;47:207-14.

14. Therasse P, Arbuck SG, Eisenhauer EA, Wanders J, Kaplan RS, Rubinstein L, et al. New guidelines to evaluate the response to treatment in solid tumors. European Organization for Research and Treatment of Cancer, National Cancer Institute of the United States, National Cancer Institute of Canada. J Natl Cancer Inst 2000;92:205-16.

15. Park JO, Lee SI, Song SY, Kim K, Kim WS, Jung CW, et al. Measuring response in solid tumors: comparison of RECIST and WHO response criteria. Jpn J Clin Oncol 2003;33:533-7.

16. Sasaki T. New guidelines to evaluate the response to treatment "RECIST" (in Japanese). Gan To Kagaku Ryoho 2000;27: 2179-84.

17. Yoshida S, Miyata Y, Ohtsu A, Boku N, Shirao K, Shimada Y. Significance of and problems in adopting response evaluation criteria in solid tumor RECIST for assessing anticancer effects of advanced gastric cancer. Gastric Cancer 2000;3:128-33.

18. Jeung HC, Rha SY, Noh SH, Roh JK, Chung HC. A phase II trial of weekly fractionated irinotecan and cisplatin for ad- 
vanced gastric cancer. Cancer Chemother Pharmacol 2007;59: 313-20.

19. Burge ME, Smith D, Topham C, Jackson DP, Anthoney DA, Halstead F, et al. A phase I and II study of 2-weekly irinotecan with capecitabine in advanced gastroesophageal adenocarcinoma. Br J Cancer 2006;94:1281-6.

20. Ott K, Fink U, Becker K, Stahl A, Dittler HJ, Busch R, et al. Prediction of response to preoperative chemotherapy in gastric carcinoma by metabolic imaging: results of a prospective trial. J Clin Oncol 2003;21:4604-10.

21. Weber WA, Ott K, Becker K, Dittler HJ, Helmberger H, Avril NE, et al. Prediction of response to preoperative chemotherapy in adenocarcinomas of the esophagogastric junction by metabolic imaging. J Clin Oncol 2001;19:3058-65.

22. Ott K, Weber WA, Lordick F, Becker K, Busch R, Herrmann K, et al. Metabolic imaging predicts response, survival, and recurrence in adenocarcinomas of the esophagogastric junction. J Clin Oncol 2006;24:4692-8.

23. Swisher SG, Maish M, Erasmus JJ, Correa AM, Ajani JA, Bresalier R, et al. Utility of PET, CT, and EUS to identify pathologic responders in esophageal cancer. Ann Thorac Surg 2004;78: 1152-60.

24. Mandard AM, Dalibard F, Mandard JC, Marnay J, Henry-Amar M, Petiot JF, et al. Pathologic assessment of tumor regression after preoperative chemoradiotherapy of esophageal carcinoma. Clinicopathologic correlations. Cancer 1994;73:2680-6.

25. Becker K, Mueller JD, Schuhmacher C, Ott K, Fink U, Busch R, et al. Histomorphology and grading of regression in gastric carcinoma treated with neoadjuvant chemotherapy. Cancer 2003;98: 1521-30.

26. Rohatgi P, Swisher SG, Correa AM, Wu TT, Liao Z, Komaki R, et al. Characterization of pathologic complete response after preoperative chemoradiotherapy in carcinoma of the esophagus and outcome after pathologic complete response. Cancer 2005;104: 2365-72.

27. Swisher SG, Hofstetter W, Wu TT, Correa AM, Ajani JA, Komaki RR, et al. Proposed revision of the esophageal cancer staging system to accommodate pathologic response (pP) following preoperative chemoradiation (CRT). Ann Surg 2005;241: 810-7.

28. Shah MA, Yeung HW, Coit D, Trocola R, Ilson D, Randazzo J, et al. A phase II study of preoperative chemotherapy with irinotecan (CPT) and cisplatin (CIS) for gastric cancer (NCI 5917): FDG-PET/CT predicts patient outcome (Meeting Abstract). J Clin Oncol 2007;25:4502.

29. Lordick F, Ott K, Krause BJ, Weber WA, Becker K, Stein HJ, et al. PET to assess early metabolic response and to guide treatment of adenocarcinoma of the oesophagogastric junction: the MUNICON phase II trial. Lancet Oncol 2007;8:797-805.
30. Siewert JR, Lordick F, Ott K, Stein HJ, Weber WA, Becker K, et al. Induction chemotherapy in Barrett cancer: influence on surgical risk and outcome. Ann Surg 2007;246:624-31.

31. Beer AJ, Wieder HA, Lordick F, Ott K, Fischer M, Becker K, et al. Adenocarcinomas of esophagogastric junction: multidetector row CT to evaluate early response to neoadjuvant chemotherapy. Radiology 2006;239:472-80.

32. Wieder HA, Beer AJ, Lordick F, Ott K, Fischer M, Rummeny EJ, et al. Comparison of changes in tumor metabolic activity and tumor size during chemotherapy of adenocarcinomas of the esophagogastric junction. J Nucl Med 2005;46:2029-34.

33. Stahl A, Ott K, Weber WA, Becker K, Link T, Siewert JR, et al. FDG PET imaging of locally advanced gastric carcinomas: correlation with endoscopic and histopathological findings. Eur J Nucl Med Mol Imaging 2003;30:288-95.

34. Mukai $\mathrm{K}$, Ishida $\mathrm{Y}$, Okajima $\mathrm{K}$, Isozaki $\mathrm{H}$, Morimoto $\mathrm{T}$, Nishiyama S. Usefulness of preoperative FDG-PET for detection of gastric cancer. Gastric Cancer 2006;9:192-6.

35. Kim SK, Kang KW, Lee JS, Kim HK, Chang HJ, Choi JY, et al. Assessment of lymph node metastases using 18F-FDG PET in patients with advanced gastric cancer. Eur J Nucl Med Mol Imaging 2006;33:148-55.

36. Chen J, Cheong JH, Yun MJ, Kim J, Lim JS, Hyung WJ, et al. Improvement in preoperative staging of gastric adenocarcinoma with positron emission tomography. Cancer 2005;103:238390.

37. Tian J, Chen L, Wei B, Shao M, Ding Y, Yin D, et al. The value of vesicant $18 \mathrm{~F}$-fluorodeoxyglucose positron emission tomography (18F-FDG PET) in gastric malignancies. Nucl Med Commun 2004;25:825-31.

38. Mochiki E, Kuwano H, Katoh H, Asao T, Oriuchi N, Endo K. Evaluation of 18F-2-deoxy-2-fluoro-D-glucose positron emission tomography for gastric cancer. World J Surg 2004;28:247-53.

39. Wang T, Sun YE, Yu CH, Chang P, Yao SL, Tian JH, et al. Fluorine-18 fluorodeoxyglucose-positron emission tomography imaging of carcinoma of cardia or fundus of stomach (in Chinese). Zhonghua Wai Ke Za Zhi 2006;44:661-4.

40. Yun M, Lim JS, Noh SH, Hyung WJ, Cheong JH, Bong JK, et al. Lymph node staging of gastric cancer using (18)F-FDG PET: a comparison study with CT. J Nucl Med 2005;46:1582-8.

41. Shah MA, Yeung HW, Tracola R, Ilson D, Levnor A, Capanu M, et al. The charcteristics and utility of FDG-PET/CT scans in patients with localized gastric cancer (GC). Proc Am Soc Clin Oncol 2007, Abstract 2.

42. Lowy AM, Feig BW, Janjan N, Rich TA, Pisters PW, Ajani JA, et al. A pilot study of preoperative chemoradiotherapy for resectable gastric cancer. Ann Surg Oncol 2001;8:519-24. 